\section{Seed Piece Spacing Influences Yield, Tuber Size Distribution, Stem and Tuber Density, and Net Returns of Three Processing Potato Cultivars}

\author{
Stephen L. Love ${ }^{1}$ \\ University of Idaho, Aberdeen Research and Extension Center, P.O. Box AA, \\ Aberdeen, ID 83210-0530
}

\section{Asunta Thompson-Johns ${ }^{2}$ \\ Colorado State University, San Luis Valley Research Center, 0249 East RD 9 \\ North, Center, CO 81125}

Additional index words. Solanum tuberosum, plant population, plant density, economic return

\begin{abstract}
Seed piece spacing is an important economic consideration in the production of potatoes (Solanum tuberosum $\mathrm{L}$.). The optimum spacing varies with cultivar and intended market. A study was designed to determine the influence of seed piece spacing on yield, tuber size distribution, net returns, and stem and tuber density of three processing potato cultivars. Seed tubers of cultivars Russet Burbank, Frontier Russet, and Ranger Russet were planted $8,15,23,31,46,61,76$, or $91 \mathrm{~cm}$ apart at two locations in 1988 and 1989. Total, marketable (U.S. No. 1), and midsize (226-452 g tubers) yield, tuber size distribution, net profits from a representative processing contract, and stem and tuber density (number per meters of row) were determined. All three cultivars achieved highest total yields at the narrowest $(8 \mathrm{~cm})$ spacing. Maximum marketable and midsize (226-452 g) yield occurred between 15 and $31 \mathrm{~cm}$, depending on the cultivar. Size distribution shifted from a predominance of small tubers at narrow spacings to a predominance of large tubers at wide spacings, and the rate of shift was cultivar-dependent. 'Russet Burbank' showed a broad range of optimal spacing for net returns, with a maximum in the range of 23 to 46 cm. Optima for 'Frontier Russet' and 'Ranger Russet' were between 15 and $46 \mathrm{~cm}$. Of the four tuber measurements, midsize yield appeared to be best for determining optimum spacing. Marketable yield was also a useful measurement. All three cultivars gave maximum midsize yields at a stem density of 10.5 to 12.1 per meter of row and a tuber density of 23.9 to 24.9 per meter of row. Tuber density showed some promise as a predictor of optimum seed piece spacing for new cultivars.
\end{abstract}

Plant population studies were among the earliest and most common field experiments involving potatoes (Houghland and Parker, 1948). Similar work continues, with recent studies being conducted for optimizing crop production and profitability (Rex, 1991; Wurr et al., 1992). Plant population studies with potatoes are never outdated because of unique tuber characteristics of new cultivars and the changing tuber size requirements of evolving industries (Barry et al., 1981; Wurr et al., 1993).

Potato seed piece spacing influences economically important characteristics, including total yield, marketable yield, tuber size

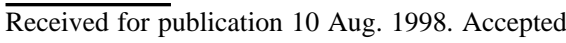
for publication 28 Nov. 1998. This research was supported in part by USDA-CSREES grant no. 9634141-2728. The cost of publishing this paper was defrayed in part by the payment of page charges. Under postal regulations, this paper therefore must be hereby marked advertisement solely to indicate this fact.

${ }^{1}$ Associate Research Professor; to whom all reprint requests should be addressed. Phone (208) $397-$ 4181;fax (208)397-4311; e-mail: slove@uidaho.edu ${ }^{2}$ Assistant Professor.
}

distribution, tuber specific gravity, and hollow heart (Barry et al., 1981; Lynch and Rowberry, 1977; Nelson et al., 1979; Rex, 1990, 1991). By impacting these characteristics, seed piece spacing and the resulting plant population have a direct influence on net returns.

Several approaches have been used to determine the optimum seed piece spacing for a cultivar. The simplest was to determine the spacing at which optimum total or marketable yield occurred (Barry et al., 1981; Lynch and Rowberry, 1977; Rex, 1990, 1991). More complex methods include optimization of financial returns or determination of the multiplication rate between the seed and the final crop (Houghland and Akeley, 1959; Strange and Blackmore, 1990). Wurr et al. (1992, 1993) suggested using a system where seed costs, tuber number, and desired tuber size in the harvested crop could be used to predict optimum spacing. This approach could provide producers with the needed spacing information for new cultivars without conducting complex and costly spacing studies.

In North America, 'Russet Burbank' is the most commonly used cultivar for frozen french fries, but two new cultivars, 'Frontier Russet' and 'Ranger Russet', are gaining popularity. Few production recommendations, including seed piece spacing, are available for these two new cultivars. Additionally, no spacing-associated economic analysis has been completed for potatoes destined for frozen french fry processing. This study had the following objectives: 1) determine optimal within-row spacing for total, marketable, and midsize yield of the potato cultivars Russet Burbank, Frontier Russet, and Ranger Russet; 2) define the effect of spacing on tuber size distribution; 3 ) determine the spacing for maximum net returns; 4 ) compare stem and tuber densities to determine if similarities exist among cultivars at optimum seed piece spacings; and 5) provide evidence as to which agronomic and economic variables are most useful for determination of optimal spacing for new cultivars. A unique characteristic of this study was the inclusion of seed piece spacings above and below the range commonly used commercially to allow establishment of trends over a broad range of conditions.

\section{Materials and Methods}

Four identical trials over 2 years were conducted at Aberdeen and Kimberly, Idaho. Certified seed potatoes of 'Russet Burbank', 'Frontier Russet', and 'Ranger Russet' were cut within a 56-70 g size range. Plots were planted 10 May in both 1988 and 1989 in a Declo silt loam soil at Aberdeen, and on 26 Apr. in both 1988 and 1989 in a Portneuf silt loam soil at Kimberly. The experimental plots were fertilized and managed according to practices typical of the respective region. Plots were harvested 3 to 5 weeks after the vines were killed (12 Oct. 1988 and 28 Sept. 1989 at Aberdeen, and on 14 Oct. 1988 and 12 Oct. 1989 at Kimberly). Individual plots were 9.1 $\mathrm{m}$ long, $2.7 \mathrm{~m}$ wide, and consisted of three rows, of which only the center row was harvested. Distance between rows was $0.9 \mathrm{~m}$, the standard width for potato production in Idaho.

Seed pieces were hand-planted in the plots to allow precise placement at $8,15,23,31,46$, 61,76 , or $91 \mathrm{~cm}$. Each spacing treatment was replicated five times within each experimental site. Early in the growing season, the number of aboveground stems in each plot was counted. After harvest, the tubers were graded, counted, and the data analyzed appropriately for the objective in question.

Total, marketable, and midsize yield. Tubers were graded into U.S. No. 1, U.S. No. 2, and cull categories, sized into 113 -g increments, and total weights in each category recorded. Total and marketable yields were calculated, with marketable yield being synonymous with U.S. No. 1 yield. Midsize yield was computed and included marketable tubers weighing from 226 to $452 \mathrm{~g}$. Homogeneity of variances within trials was confirmed for all variables, allowing the combination of years and locations. The analyses of variance (ANOVAs) were computed, first for the entire data set, then within each individual cultivar over locations and years. Regression was used to establish significant trends, or means among 
spacing treatments were separated using Fisher's protected least significant difference (LSD).

Tuber size distribution. For individual cultivars, yields of each tuber size category were plotted three-dimensionally against spacing treatment. ANOVA was completed for yield within each size category. Comparisons were made of distribution changes across spacing treatments.

Net returns. Net returns for each cultivar and spacing combination were computed in U.S. dollars per hectare using a representative processing industry contract formula, with incentives for size and grade components. A paid yield was calculated that included the U.S. No. 1 and U.S. No. 2 tubers, but excluded undersized $(<113 \mathrm{~g})$ and cull tubers. A representative industry base price of $\$ 0.1012$ per kilogram was used. Incentive amounts were added to this base price and calculated as follows: the number of percentage points, above $50 \%$, of U.S. No. 1 tubers was multiplied by $\$ 0.00022$ per kilogram; the number of percentage points above $22 \%$ of tubers $>283 \mathrm{~g}$ within the paid yield was multiplied by $\$ 0.00044$ per kilogram. Because the size grading process did not divide the tubers at $283 \mathrm{~g}$, the weight of tubers between 226 and $339 \mathrm{~g}$ was divided by 2 and added to the weight of tubers $>339 \mathrm{~g}$ to calculate this percentage. The gross returns were calculated by multiplying the paid yield $\times$ the base price plus incentives price.

Production costs were calculated using a partial budgeting approach, with seed costs due to treatments being the only variable altered. Base costs were taken from the 1995 Idaho Potato Costs and Returns Estimates (Patterson et al., 1997). From the base costs, the seed costs and the portion of the interest on the operating loan that resulted from seed purchase were subtracted. Seed costs were recalculated for each spacing treatment, then added back into the base costs. Net returns were calculated as gross returns minus production costs. Analysis of variance was completed as described for the yield variables.

Stem and tuber density. Aboveground stems and tubers produced per plot were counted and means and density calculated. A secondary objective was to determine if the maximum midsize (226-452 g) tuber yield occurred at or near the same stem or tuber density for each cultivar. A nonlinear, parabolic equation for midsize yield vs. seed piece spacing was fitted to the data from each cultivar using SAS Procedure Nlin (SAS Institute, 1993). Only data from the 8-, 15-, 23-, and 31-cm spacing treatments were used, because the maxima for midsize yield fell within this range and inclusion of the wider spacing treatments resulted in a poor fit for the parabolic function. From the equation, the spacing corresponding to predicted maximum midsize yield was computed. Two linear equations, one for stem and one for tuber density vs. seed piece spacing, were created for each cultivar. The equations were used to predict the stem and tuber density corresponding to the maximum midsize yield obtained previously via the parabolic equations.

\section{Results}

A comprehensive ANOVA of combined data from all sites and years showed the following significant $(P \leq 0.05)$ main effects: trial site and seed piece spacing for total yield; trial site, seed piece spacing, and cultivar for marketable yield; trial site and seed piece spacing for midsize yield; and trial site, seed piece spacing, and cultivar for net profit. Spacing treatment $\times$ cultivar interactions were significant for marketable yield, midsize yield, and net profit, but not for total yield. The ANOVA for individual cultivars revealed significant $(P \leq 0.05)$ trial site and spacing effects for total yield, marketable yield, midsize yield, and net profit in the case of each cultivar. Statistical comparisons presented in the body of the paper were made using results of the ANOVAs for individual cultivars.

Total and marketable yield. Total yield of all three cultivars was highest at the closest spacing and steadily decreased in a linear fashion as the spacing widened (Fig. 1). The total yields were similar for each cultivar at each spacing treatment. At the 8-cm spacing, 'Russet Burbank' produced a total of $60.8 \mathrm{t} \cdot \mathrm{ha}^{-1}$, 'Frontier Russet' 63.9, and 'Ranger Russet' 65.7. At $91 \mathrm{~cm}$, the yield of the three cultivars was $39.1,39.0$, and $37.0 \mathrm{t} \cdot \mathrm{ha}^{-1}$, respectively. This similarity among cultivars was reflected as a nonsignificant cultivar effect in the comprehensive ANOVA.

Marketable yield differed significantly $(P$ $\leq 0.05$ ) among cultivars (Fig. 1). Of the three cultivars, 'Russet Burbank' had the lowest marketable yield across all spacing treatments $\left(29.3 \mathrm{t} \cdot \mathrm{ha}^{-1}\right)$, because of its tendency to produce small and malformed tubers. The significant cultivar effect in the comprehensive ANOVA for marketable yield was due to this difference. 'Frontier Russet' and 'Ranger Russet' were similar in marketable yield across all spacing treatments $\left(33.5\right.$ and $33.8 \mathrm{t} \cdot \mathrm{ha}^{-1}$, respectively). Among individual spacing treatments, 'Russet Burbank' and 'Frontier Russet' reached their highest numerical marketable yield at $23 \mathrm{~cm}$ (36.7 and $41.5 \mathrm{t} \cdot \mathrm{ha}^{-1}$,

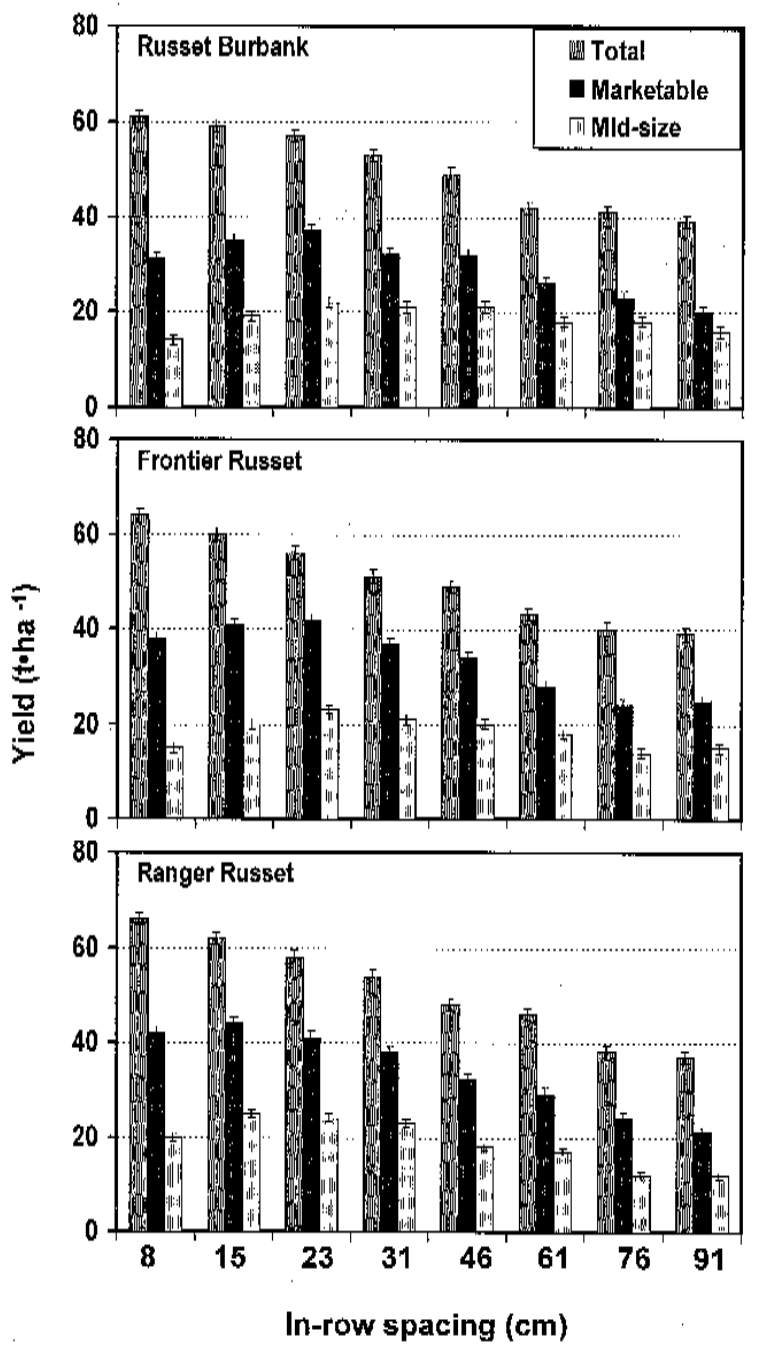

Fig. 1. Effects of within-row seed piece spacing treatments on total, marketable (U.S. No. 1), and midsize (226-452 g) tuber yield for the potato cultivars Russet Burbank, Frontier Russet, and Ranger Russet. Standard error bars provide statistical comparisons within the marketable and midsize (226-452 g) categories. Linear regression equations for total yield for the three cultivars were: 'Russet Burbank', total yield $=$ spacing $(-6.41)+558.1$; 'Ranger Russet', total yield $=$ spacing $(-7.92)+592.0$; and 'Frontier Russet', total yield $=$ spacing $(-6.80)+565.9$. Both intercept and slope parameter estimates were significantly $(P \leq 0.005)$ different from zero for all three cultivars. 


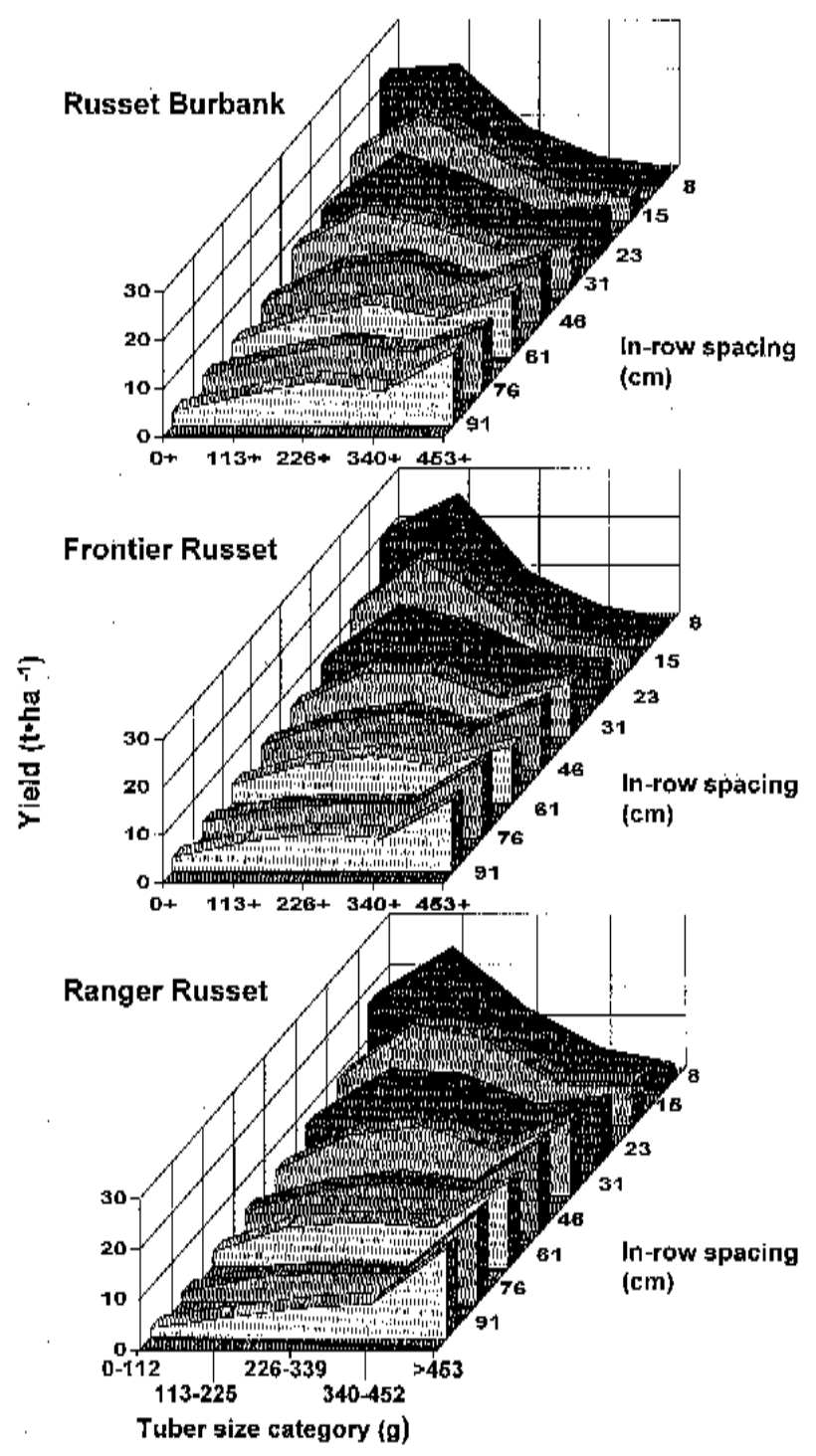

Fig. 2. Effects of in-row seed piece spacing on yield of tubers in each of five size categories for the cultivars Russet Burbank, Frontier Russet, and Ranger Russet.

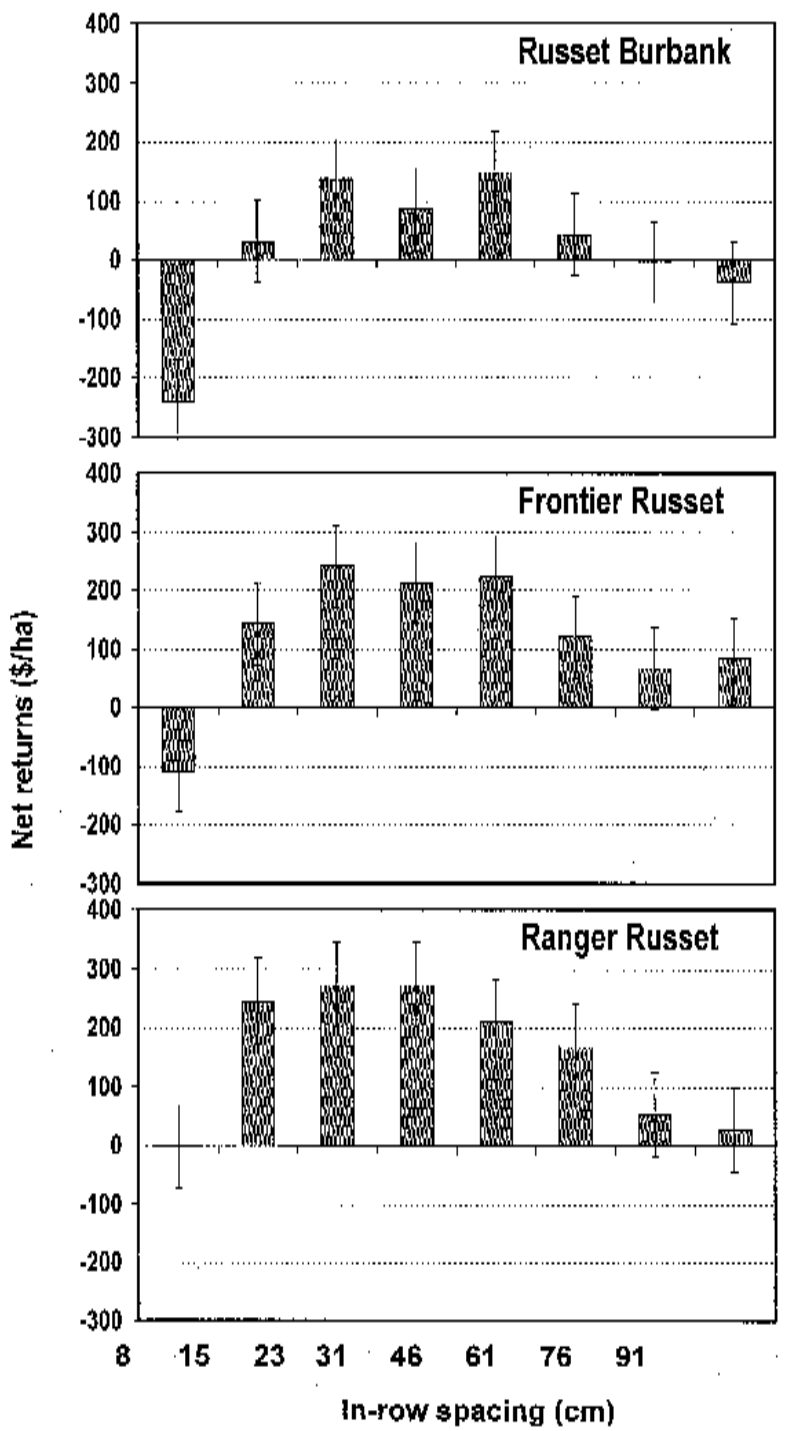

Fig. 3. Effects of seed piece spacing on net returns for the cultivars Russet Burbank, Frontier Russet, and Ranger Russet. respectively), although there was no statistically significant difference between 15 and 23 $\mathrm{cm}$ for either cultivar. 'Ranger Russet' marketable yield was highest at $15 \mathrm{~cm}\left(43.6 \mathrm{t} \cdot \mathrm{ha}^{-1}\right)$, with no statistical significance between the 8-, $15-$, or 23-cm spacing.

Midsize (226-452 g tubers) yield response of the three cultivars was similar to that of total yield, in that cultivar means were nearly identical, and not significantly different, when averaged across all spacing treatments. Midsize yields were $19.0,18.5$, and $18.3 \mathrm{t} \cdot \mathrm{ha}^{-1}$ for 'Ranger Russet', 'Russet Burbank', and 'Frontier Russet', respectively. The highest midsize yield did not occur at the same spacing for all cultivars (Fig. 1). Numerically, 'Russet Burbank' and 'Frontier Russet' had the highest midsize yield at the $23-\mathrm{cm}$ spacing (21.5 and $23.0 \mathrm{t} \cdot \mathrm{ha}^{-1}$, respectively), while 'Ranger Russet' had the highest at $15 \mathrm{~cm}\left(25.3 \mathrm{t} \cdot \mathrm{ha}^{-1}\right)$. For 'Russet Burbank' no significant differences existed among the 15-, 23-, 31-, or 46$\mathrm{cm}$ spacings, for 'Frontier Russet' among the $15-, 23-$, or 31-cm spacings, and for 'Ranger
Russet' between the 15- and 23-cm spacings.

Tuber size distribution. Within each cultivar, ANOVA showed significant differences among spacing treatments for yield within each size category. Changes in tuber size distribution associated with increased spacing were somewhat similar among cultivars, although subtle differences were observed (Fig. $2)$. At the $8-\mathrm{cm}$ spacing, all three cultivars produced a large majority of tubers in the two smallest size categories (0-112 and 113-225 g) and had almost no tubers in the $>452 \mathrm{~g}$ (oversize) category. As the spacing widened, the tubers became larger, with a greater proportion in the $>452 \mathrm{~g}$ category. At the widest spacing $(91 \mathrm{~cm})$, the percentage of $>452 \mathrm{~g}$ tubers ranged from $37 \%$ for 'Russet Burbank' to $49 \%$ for 'Ranger Russet'.

At the narrowest spacing, $74 \%$ of the 'Russet Burbank' tubers were in the two smallest size categories, with approximately equal amounts in each (Fig. 2). When planted 15-31 $\mathrm{cm}$ apart, the 113-225 g size range had proportionally more tubers than other size catego- ries. When planted 46 or more $\mathrm{cm}$ apart, the oversize category was dominant, but there was a consistent secondary peak at the 226-339 g tuber size category.

'Frontier Russet' was similar to 'Russet Burbank' in that $75 \%$ of its tubers were in the smallest two categories when planted at $8 \mathrm{~cm}$. However, in contrast to 'Russet Burbank', a substantially greater proportion of tubers was in the 113-225 g size range rather than the 0112 g category (Fig. 2). As the spacing became wider, the shift of tubers to larger categories occurred more rapidly for 'Frontier Russet' than for 'Russet Burbank'. As with 'Russet Burbank', at the wider-spacing treatments 'Frontier Russet' tended to have a secondary peak in the distribution within the 226-339 $\mathrm{g}$ category.

Only $64 \%$ of 'Ranger Russet' tubers were in the smallest two categories when planted at $8 \mathrm{~cm}$. A greater proportion of these smaller tubers was in the 113-225 g range, rather than the $0-112 \mathrm{~g}$ category, than was the case for 'Russet Burbank' (Fig. 2). In contrast with the 
other two cultivars, 'Ranger Russet' produced the highest yield of tubers in the oversize category when the spacing was $31 \mathrm{~cm}$ or wider. The shift toward oversize tubers was more extreme for 'Ranger Russet' than for the other cultivars at the widest spacing treatments and there was no secondary peak in the distribution at the 226-339 $\mathrm{g}$ or any other size category.

Net returns. Based on a representative processing contract, 'Ranger Russet' produced the greatest average net return of the three cultivars, followed by 'Frontier Russet' and 'Russet Burbank' (Fig. 3). Highest net return at optimum spacing for 'Ranger Russet' (25cm spacing) was almost double that for 'Russet Burbank' because of higher paid yield with 'Ranger Russet' and higher adjusted price resulting from a larger proportion of marketable and large tubers. Net returns for all three cultivars were low (negative) at the narrowest spacing, increased to a maximum, then declined to low or negative values at the widest spacing.

The method of calculating net returns created a great deal of variability in the data. Coefficients of variation for net profits were 103.4, 83.6, and 640.4 for 'Frontier Russet', 'Ranger Russet', and 'Russet Burbank', respectively. This variability made separation of means for net returns difficult. The result was a broad range of spacings for all three cultivars that could not be discounted as optimum. 'Russet Burbank' had what appeared to be a bimodal distribution of net returns with the peaks at $23 \mathrm{~cm}(\$ 36.34 / \mathrm{ha})$ and $46 \mathrm{~cm}(\$ 147.35 /$ ha), although differences among the 23-, 31-, or 46-cm spacings were nonsignificant. 'Russet Burbank' showed losses at the 8-, 76-, and 91-cm spacing treatments. 'Frontier Russet' produced its highest net returns at the $23-\mathrm{cm}$ spacing treatment, with slightly lower and statistically similar net returns at 31 and 46 $\mathrm{cm}$. The range near the optimum was broad, and only the 8-cm spacing resulted in a loss. 'Ranger Russet' showed a somewhat bellshaped distribution of net returns and produced statistically similar profits when planted at $15,23,31$, or $46 \mathrm{~cm}$.

Stem and tuber density. Seed piece spacing had a significant effect on number and density of both aboveground stems and tubers. Although statistically significant $(P \leq 0.05)$, a biologically insignificant range of only 0.2 (from 2.2 to 2.4) stems per plant occurred among the spacing treatments across the three cultivars. Evaluation of the linear component of spacing within each variety resulted in nonsignificant changes within each cultivar for stem number across spacings (Table 1). Because stem numbers changed little with spacing, the average stem density across cultivars changed more than 10-fold (from 2.6 to 29.8 stems per meter of row) as the spacing decreased from 91 to $8 \mathrm{~cm}$. In contrast with stem number, both tuber number per plant and tuber density showed the effects of differential competition imposed by the spacing treatments. Average tuber number per plant across all cultivars increased from three at the $8-\mathrm{cm}$ spacing to nearly 10 at $91 \mathrm{~cm}$, concomitant with a 4-fold decrease in tuber density (from 38.8 to 10.6 tubers per meter of row).

Spacing $\times$ cultivar interactions were significant for stem density, tuber number, and tuber density (Table 1). The linear component of spacing was significant for stem density, tuber number, and tuber density for all three cultivars. Inspection of interaction means revealed that all three cultivars responded similarly for these three variables and that the interactions were a result of degree rather than type of reaction. In general, 'Ranger Russet' was slightly less responsive to changes in spacing than were the other two cultivars.

Rank of the three cultivars from most to least, with respect to stems and tubers per plant, were 'Russet Burbank', 'Frontier Russet', and 'Ranger Russet' (Table 2). The predicted midsize yield maxima, derived using a parabolic function, followed the same cultivar rank. By using linear equations (see footnotes, Table 2) to model stems and tubers per meter of row (referred to as stem and tuber density) over the spacing treatments, a predicted value for these variables at the midsize yield maximum was computed for each cultivar. The optimum stem density for midsize yield for the three cultivars fell within a narrow range (10.512.1 ), while the range for tuber density was even narrower (23.9-24.9). Because all degrees of freedom were used in model development, differences between cultivars for predicted stem and tuber density could not be analyzed. However, the similarity among cultivars suggested that tuber density may have

Table 1. Influence of potato seed piece spacing on the number and density of stems and tubers of three cultivars.

\begin{tabular}{|c|c|c|c|c|}
\hline Spacing $(\mathrm{cm})$ & Stems/plant & Stems $/ \mathrm{m}^{2}$ & Tubers/plant & Tubers $/ \mathrm{m}^{2}$ \\
\hline \multicolumn{5}{|c|}{ Frontier Russet } \\
\hline 8 & 2.2 & 28.7 & 3.0 & 39.8 \\
\hline 15 & 2.1 & 14.1 & 4.5 & 29.8 \\
\hline 23 & 2.2 & 9.7 & 5.4 & 23.4 \\
\hline 31 & 2.1 & 6.9 & 5.8 & 19.2 \\
\hline 46 & 2.3 & 5.0 & 7.7 & 16.7 \\
\hline 61 & 2.3 & 3.8 & 8.4 & 13.8 \\
\hline 76 & 2.3 & 3.0 & 9.0 & 11.8 \\
\hline 91 & 2.4 & 2.6 & 10.1 & 11.0 \\
\hline Significance & $\mathrm{L}^{\mathrm{Ns}}$ & $\mathrm{L}^{* *}$ & $\mathrm{~L}^{* *}$ & $\mathrm{~L}^{* *}$ \\
\hline \multicolumn{5}{|c|}{ Ranger Russet } \\
\hline 8 & 1.9 & 25.5 & 2.8 & 36.1 \\
\hline 15 & 1.9 & 12.5 & 4.1 & 26.8 \\
\hline 23 & 2.0 & 8.6 & 5.0 & 22.1 \\
\hline 31 & 1.9 & 6.3 & 5.3 & 17.4 \\
\hline 46 & 2.1 & 4.6 & 6.6 & 14.4 \\
\hline 61 & 2.1 & 3.5 & 8.2 & 13.4 \\
\hline 76 & 1.9 & 2.5 & 7.5 & 9.9 \\
\hline 91 & 2.1 & 2.3 & 8.6 & 9.4 \\
\hline Significance & $\mathrm{L}^{\mathrm{Ns}}$ & $\mathrm{L}^{* *}$ & $\mathrm{~L}^{* *}$ & $\mathrm{~L}^{* *}$ \\
\hline \multicolumn{5}{|c|}{ Russet Burbank } \\
\hline 8 & 2.7 & 34.8 & 3.1 & 40.5 \\
\hline 15 & 2.8 & 18.3 & 4.6 & 30.1 \\
\hline 23 & 2.6 & 11.4 & 5.7 & 25.1 \\
\hline 31 & 2.5 & 8.2 & 6.7 & 21.9 \\
\hline 46 & 2.5 & 5.6 & 7.5 & 16.3 \\
\hline 61 & 2.6 & 4.3 & 8.4 & 13.7 \\
\hline 76 & 2.7 & 3.5 & 9.8 & 12.8 \\
\hline 91 & 2.7 & 3.0 & 10.3 & 11.3 \\
\hline Significance & $\mathrm{L}^{\mathrm{Ns}}$ & $\mathrm{L}^{* *}$ & $\mathrm{~L}^{* *}$ & $\mathrm{~L}^{* *}$ \\
\hline
\end{tabular}

${ }^{2}$ Tuber density was expressed as tubers per meter of row (= tubers per $\left.0.91 \mathrm{~m}^{2}\right)$.

ws, ***Nonsignificant or significant at $P \leq 0.01$, respectively, for linear (L) components of plant spacing as measured using orthogonal contrasts. value in determining seed piece spacing for optimization of midsize tuber yield.

\section{Discussion}

A major reason for conducting this study was to gather information allowing determination of agronomic or economic variables that may be used in spacing optimization studies. Total yield appears to be of little use in determining optimum spacing. For all three cultivars, the highest total yield occurred at the narrowest spacing, then declined as spacing widened. In contrast, the marketable and midsize yield variables gave more promising results. Both reached a definite maximum in the range of the $15-$ to $31-\mathrm{cm}$ spacing with peak location dependent on cultivar. 'Russet Burbank' had maximum marketable yield at the 23-cm spacing and maximum midsize yield between 23 and $31 \mathrm{~cm}$ (the predicted maximum from Table 2 was $24.6 \mathrm{~cm}$ ). These spacings are in the lower range of those used commercially in southern Idaho.

Economic analysis has some attractive features for determination of optimum spacing. It simultaneously reflects the value of the crop and incorporates the costs involved with changing spacing. However, this study revealed some weaknesses in the economic analysis employed here. The inclusion of economic variables substantially increased the variability of the data, making separation of means for spacing treatments difficult and leading to confusion as to the spacing at which net re- 
Table 2. Average number of stems per plant, tubers per plant, predicted seed piece spacing at which maximum midsize yield occurs, and predicted number of stems and tubers per meter at which midsize tuber yield occurs for three cultivars of potato, based upon four spacing treatments ranging from 8 to 31 $\mathrm{cm}$.

\begin{tabular}{|c|c|c|c|c|c|}
\hline Cultivar & Stems/plant & Tubers/plant & $\begin{array}{c}\text { Predicted } \\
\text { spacing at } \\
\text { midsize } \text { max }^{\mathrm{z}}\end{array}$ & $\begin{array}{c}\text { Predicted } \\
\text { stems/m at } \\
\text { midsize max }{ }^{y}\end{array}$ & $\begin{array}{c}\text { Predicted } \\
\text { tubers } / \mathrm{m} \text { at } \\
\text { midsize } \max ^{\mathrm{x}}\end{array}$ \\
\hline Russet Burbank & 2.6 & 5.0 & 24.6 & 12.1 & 24.9 \\
\hline Frontier Russet & 2.2 & 4.7 & 23.6 & 10.5 & 24.3 \\
\hline Ranger Russet & 1.9 & 4.3 & 20.8 & 11.8 & 23.9 \\
\hline
\end{tabular}

${ }^{\mathrm{z}}$ Predicted using a parabolic nonlinear function.

yPredicted using the following linear equations: 'Russet Burbank', stems per meter (SPM) $=-1.14$ (spacing) + 39.9; 'Frontier Russet', SPM = -0.91 (spacing) + 32.3; 'Ranger Russet', SPM = -0.81 (spacing) + 28.7 'Predicted using the following linear equations: 'Russet Burbank', tubers per meter (TPM) $=-0.80$ (spacing) + 44.5; 'Frontier Russet', TPM =-0.90 (spacing) + 45.1; 'Ranger Russet', TPM = -0.80 (spacing) + 40.8 .

turns were maximized. Another problem was the artificially high value that occurred at the wider spacing treatments. This was partially a result of the incentive clause for tubers $>283 \mathrm{~g}$; the wider the spacing, the higher the percentage of large tubers (Table 2). However, tubers $>452 \mathrm{~g}$ are difficult to utilize by processors and fresh-market buyers alike and are therefore of limited value. The large tuber incentive does not account for this and gives a false high value to tubers produced under wide spacing situations. This incentive was designed for 'Russet Burbank', which, under traditional spacing conditions (23-35 cm), tends to produce many undersized tubers. The incentive was never intended to be used under some of the conditions produced by this study, such as those resulting from the spacing treatments at or above $46 \mathrm{~cm}$. Numerically, 'Russet Burbank' unexpectedly reached its highest net return value at the 46- $\mathrm{cm}$ spacings, wider than is ever used commercially in Idaho.

Neither marketable nor midsize yields were prone to the anomalies present in the economic analysis. Both variables partially reflect crop value by including potatoes for which growers are financially compensated. Of the two variables, midsize yield is probably the most important because it includes marketable tubers most valuable to both freshmarket and processing buyers. If the response of these three cultivars is typical, maximizing midsize yield by optimizing seed piece (or plant) spacing should be an appropriate approach for developing recommendations for new cultivars.

Response of tuber size distribution to spacing varied with cultivar, resulting in spacingdependent differences in yield and net returns. 'Ranger Russet' showed a greater tendency to produce marketable-sized tubers at the narrowest spacings, and oversized tubers at the widest spacings, than did 'Russet Burbank'; whereas 'Frontier Russet' was intermediate in its response. Thus, 'Ranger Russet' produced its highest marketable and midsize yields at a narrower spacing than 'Russet Burbank', and 'Frontier Russet' was intermediate.

This study provided sufficient information to allow determination of optimum spacing for 'Russet Burbank' and more importantly, for 'Frontier Russet' and 'Ranger Russet'. There was some uncertainty inherent in determining yield maximums using ANOVA and means separation by LSD. The highest numerical value for marketable and midsize yield was not always significantly different from the values for adjacent spacing treatments. However, the yield values for the narrowest and widest spacings were consistently lower statistically, suggesting the presence of a peak. This was verified by the good fit of the parabolic equation to the midsize yield data. This peak value could be approximated from the graphs or predicted using the parabolic equation. The predicted optimum spacings for maximizing midsize yields were 24.6, 23.6, and $20.8 \mathrm{~cm}$ for 'Russet Burbank', 'Frontier Russet', and 'Ranger Russet', respectively (Table 2).

Stem and tuber numbers differed in response to seed piece spacing. Stem number per plant remained almost constant as spacing changed, whereas stem density changed. In contrast, tuber numbers per plant decreased as spacing narrowed and competition increased. As a result, tuber density changed less drastically with spacing treatment than did stem density.

One objective of this study was to estimate the value of stem or tuber density as an indicator of optimum spacing. Is optimum spacing identical for all cultivars? If so, one of these variables could replace harder-to-measure yield variables in spacing studies. A minimum number of spacing treatments would provide sufficient data to allow prediction of optimum spacing.
Among the three cultivars there was a 27\% difference from highest to lowest numbers of stems per plant and a $14 \%$ difference for tubers per plant (Table 2). Calculation of the density corresponding to maximum midsize yield reduced these differences to $13 \%$ for stem density and $4 \%$ for tuber density. These differences could not be tested statistically because all degrees of freedom were used in model construction. However, average tuber density among cultivars was almost identical and may be sufficiently close to serve as a good indicator of optimum spacing. This idea must be tested further in trials with cultivars expressing a wider range of tuber numbers and under conditions permitting an appropriate statistical procedure.

\section{Literature Cited}

Barry, P., T.S. Storey, and T. Quinlivan. 1981. Effect of population and seed size on the yield of two maincrop potato cultivars. Irish J. Agr. Res. 20:71-79.

Houghland, G.V.C. and R.V. Akeley. 1959. Effects of seed spacing and fertilizer rate on field performances of potato varieties and on financial return. Amer. Potato J. 36:227-234.

Houghland, G.V.C. and M.M. Parker. 1948. A study of three factors in potato production: Row spacing, seed spacing, and fertilizer rate. Amer. Potato J. 25:393-406.

Lynch, D.R. and R.G. Rowberry. 1977. Population density studies with 'Russet Burbank' II. The effect of fertilization and plant density on growth, development and yield. Amer. Potato J. 54:57-71.

Nelson D.C., D.A. Jones, and M.C. Thoreston. 1979. Relationships between weather, plant spacing, and the incidence of hollow heart in Norgold Russet potatoes. Amer. Potato J. 56:581-586.

Patterson, P.E., W.H. Bohl, and R.L. Smathers. 1997. 1997 Southeastern Idaho crop costs and returns estimate: Russet Burbank commercial potatoes: No storage. Univ. of Idaho Coop. Ext. Publ. EBB4-Pol-97, Moscow, Idaho.

Rex, B.L. 1990. Effect of seed piece population on the yield and processing quality of 'Russet Burbank' potatoes. Amer. Potato J. 67:473-489.

Rex, B.L. 1991. The effect of in-row seed piece spacing and harvest date on the tuber yield and processing quality of Conestoga potatoes in southern Manitoba. Can. J. Plant Sci. 71:289-296.

Strange, P.C. and K.W. Blackmore. 1990. Effect of whole seed tubers, cut seed and within row spacing on potato (cv. Sebago) tuber yield. Austral. J. Expt. Agr. 30:427-431.

Wurr, D.C.E., J.R. Fellows, and E.J. Allen. 1992. Determination of optimum tuber planting density in the potato varieties Pentland Squire, Cara, Estima, Maris Piper and King Edward. J. Agr. Sci., Cambridge, U.K., 119:35-44.

Wurr, D.C.E., J.R. Fellows, and E.J. Allen. 1993. An approach to determining optimum tuber planting densities in early potato varieties. J. Agr. Sci., Cambridge, U.K., 120:63-70. 